\title{
Association between occupational exposure and the clinical characteristics of COPD
}

\author{
Denis Caillaud ${ }^{1 *}$, Franck Lemoigne ${ }^{2}$, Philippe Carré ${ }^{3}$, Roger Escamilla ${ }^{4}$, Pascal Chanez ${ }^{5}$, Pierre-Régis Burgel ${ }^{6}$, \\ Isabelle Court-Fortune ${ }^{7}$, Gilles Jebrak ${ }^{8}$, Christophe Pinet ${ }^{9}$, Thierry Perez ${ }^{10}$, Graziella Brinchault ${ }^{11}$, \\ Jean-Louis Paillasseur ${ }^{12}$, Nicolas Roche ${ }^{13}$ on behalf of the initiatives BPCO Scientific Committee
}

\begin{abstract}
Background: The contribution of occupational exposures to COPD and their interaction with cigarette smoking on clinical pattern of COPD remain underappreciated. The aim of this study was to explore the contribution of occupational exposures on clinical pattern of COPD.

Methods: Cross-sectional data from a multicenter tertiary care cohort of 591 smokers or ex-smokers with COPD (median FEV1 49\%) were analyzed. Self-reported exposure to vapor, dust, gas or fumes (VDGF) at any time during the entire career was recorded.

Results: VDGF exposure was reported in 209 (35\%) subjects aged 31 to 88 years. Several features were significantly associated with VDGF exposure: age (median 68 versus 64 years, $p<0.001$ ), male gender (90\% vs 76\%; $p<0.0001$ ), reported work-related respiratory disability ( $86 \%$ vs $7 \%, p<0.001)$, current wheezing $(71 \%$ vs $61 \%, p=0.03)$ and hay fever $(15.5 \%$ vs $8.5 \%, p<0.01)$. In contrast, current and cumulative smoking was less $(p=0.01)$ despite similar severity of airflow obstruction.

Conclusion: In this patient series of COPD patients, subjects exposed to VDGF were older male patients who reported more work-related respiratory disability, more asthma-like symptoms and atopy, suggesting that, even in smokers or ex-smokers with COPD, occupational exposures are associated with distinct patients characteristics.
\end{abstract}

Keywords: Occupational, COPD, Exposure assessment

\section{Background}

Chronic obstructive pulmonary disease (COPD) is currently viewed as a consequence of interactions between genetic and environmental factors. Tobacco smoking is the most important risk factor for COPD [1], but other environmental factors such as occupational exposures are likely to contribute in some patients [2]. In 2010, the American Thoracic Society estimated that more than $20 \%$ of COPD cases are attributable to occupational exposure [3].

Most studies documenting the association between COPD and occupational exposures have been performed in workplace settings or in general population samples and community-based cohorts. Only one patient series

\footnotetext{
* Correspondence: dcaillaud@chu-clermontferrand.fr

${ }^{1}$ Service de Pneumologie, Hôpital Gabriel Montpied, Montalembert Str, Clermont-Ferrand, 63003, France

Full list of author information is available at the end of the article
}

specifically assessed the characteristics of COPD patients with a history of occupational exposures. Historically, the identification of work-related COPD has been based on the observation of an excess occurrence of COPD among exposed workers in specific industries [4]. Subsequently, general population-based studies such as the ECRHS [5] or community-based cohorts of patients with COPD [6-8] found an increased risk of COPD in subjects exposed to vapors, dust, gas, fumes (VDGF) or working in agricultural, paper, cleaning, wood and food processing industries. In the only available series of COPD patients $(n=185)$, VDGF exposure was associated with sputum production and increased dyspnea [9]. In most studies, occupational exposures were assessed using questionnaires with broad terms encompassing multiple exposures (VDGF), which appear reasonably effective in identifying subjects significantly exposed to occupational air pollutants [10].

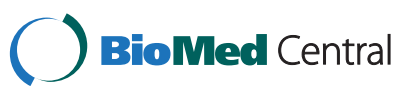


Regarding the clinical and lung function characteristics of COPD, it might be hypothesized that occupational exposures could be associated with specific phenotypic traits such as atopy, since many occupational air pollutants have sensitizing properties that could interact with genetic predisposition [11]. However, this hypothesis has not been adequately tested yet.

The present analysis was designed to explore the influence of occupational exposures on disease characteristics in in a patient series of 591 smokers or ex-smokers with well-defined COPD.

\section{Methods}

\section{Population}

The present study is based on the analysis of crosssectional data from a previously described cohort of COPD patients recruited between January 2005 and August 2008 in 17 university respiratory medicine departments located throughout France [12]. Respiratory physicians prospectively recruited smokers or ex-smokers $(>10$ pack-years cumulative tobacco consumption) in stable condition (no history of exacerbation requiring medical treatment for the previous 4 weeks) with a GOLD (Global Initiative on Obstructive Lung Disease)-based diagnosis of COPD (postbronchodilator $\mathrm{FEV}_{1} / \mathrm{FVC}$ ratio $<70 \%$ ) [13]. Patients with a main diagnosis of bronchiectasis, asthma or any significant respiratory disease other than COPD were excluded. The study was approved by the Ethics Committee of Versailles (France) and all patients provided informed written consent.

\section{Data collection}

We used a standardized case report form that covered demographic data, cumulative tobacco smoking, and clinical and lung function characteristics in stable condition. Symptoms of chronic bronchitis and dyspnea were evaluated using questions derived from the European Community Respiratory Health Survey (ECRHS). Current (during the previous year) history of sputum production and wheezing was assessed [14]. Pulmonary function tests were performed according to international standards [15]. The number of self-reported acute exacerbations of COPD was assessed and exacerbations were classified as mild, moderate (use of antibiotics or oral corticosteroids) or severe (hospitalization or emergency department visit). Health related quality of life was evaluated using the Saint George's Respiratory Questionnaire (SGRQ) [14].

\section{Risk factors}

Prior occupational exposures were assessed by the following ECRHS-derived question: "Have you ever worked in a job which exposed you to vapors, dust, gas, or fumes?" [5]. A history of transient work-related respiratory disability was assessed by the question: "Have you ever had to stop transiently your job because it affected your breathing? "Permanent work-related respiratory handicap was defined by a positive answer to the question "Have you ever had to stop definitely your job because it affected your breathing?". Patients who reported VDGF exposure were questioned on the job position that they occupied during the longest period of time. Answers were analyzed using a previously published specific job exposure matrix (JEM) that provided a semiquantitative estimate (none, low or high) of exposure to three broad categories of agents: organic dust, mineral dust, or gas/fumes [16,17].

Patients were categorized (i) as current smokers or exsmokers (smoking cessation at least 12 months ago) and (ii) as smokers or ex-smokers of $\geq$ or $<20$ pack-years [16].

Patients were considered as atopic when they reported a history of hay fever.

\section{Statistical analysis}

Since some variables were not continuously distributed, data are reported as median [Q1-Q3] for quantitative variables. Percentages were used to describe categorical variables. Univariate comparisons between patients exposed or not to VDGF were performed using Chisquare test for qualitative variables and the two-sided non-parametric Wilcoxon test for quantitative variables.

A p value $<0.05$ was considered for statistical significance. Analysis was performed with SAS software (version 9.2).

\section{Ethic statement}

The research protocol was approved by the ethics committee of Versailles (France) and all patients provided informed written consent.

\section{Results}

Analysis of demographic characteristics and risk factors in COPD subjects according to VDGF exposure

Among the 615 COPD patients included in the cohort, required data were available in 591 (96\%). Exposure to VDGF was reported by 209 subjects (35\%) and was more common among males than females $(90 \%$ vs $10 \%$, Table 1). The median age was 65 years, patients reporting VDGF exposure being about 4 years older than VDGF- subjects. Altogether, $27 \%$ of patients were still current smokers at inclusion in the cohort. Cumulative smoking was 41 (26-57) pack-years. Current and cumulative smoking were also less in COPD patients with VDGF exposure, despite similar severity of airflow obstruction (see following table). Cumulative smoking and FEV1 (\% predicted) were not correlated $(r=0.08)$. With regard to atopy, hay fever was almost twice more frequent in the VDGF + population. A trend towards a 
Table 1 Characteristics of the study population $(\mathrm{N}=591)$ : data are median [Q1-Q3]

\begin{tabular}{|c|c|c|c|c|}
\hline & All $n=591$ & VDGF + n = 209 (35\%) & VDGF - $n=382(65 \%)$ & $\mathbf{P}$ \\
\hline Male/female ratio (\%) & $80.7 / 19.3$ & $89.9 / 9.1$ & $75.6 / 24.4$ & $<0.001(a)$ \\
\hline Age & 65 [57-73] & $68[59-74]$ & $64[57-72]$ & $0.0005(b)$ \\
\hline Smoking status Current/past (\%) & $27 / 73$ & $22 / 78$ & $29 / 71$ & $0.04(a)$ \\
\hline Smoking, pack-yr & $41[26-58]$ & $39[20-54]$ & $42[28-60]$ & $0.01(b)$ \\
\hline Hay fever & 11 & 15.5 & 8.5 & $<0.01$ (a) \\
\hline Life-time atopic dermatitis & 7 & 8.8 & 6.1 & NS (a) \\
\hline Life-time asthma & 11.3 & 14.7 & 9.5 & $0.0614(\mathrm{a})$ \\
\hline
\end{tabular}

(a) $=$ Chi-Square Test.

(b) = Wilcoxon rank-sum test.

$p$ values are for differences between VGDF + and VGDF-

similar association was found for life-time asthma. FEV1 and GOLD stage did not differ between exposed and non-exposed subjects. They were not influenced by the level of cumulative smoking.

Among patients reporting VDGF exposure, job-exposure matrix (JEM) analysis found that $61 \%$ were exposed to mineral dusts, $34 \%$ to biological pollutants and $73 \%$ to gas, vapors or fumes. Altogether, $3 \%$ of the whole patient population were exposed to one category of pollutants, $20 \%$ to two and $8 \%$ to three categories. Current smokers were less represented among subjects exposed to mineral dusts (17\% vs $30 \%$ in the remaining population) and to vapors, gas and fumes (20\% vs $29 \%)$.

\section{Symptoms and health status}

In terms of symptoms, although chronic bronchitis was not more frequent among VDGF + COPD patients (overall prevalence: 73\%), they reported current sputum production more often. Similarly, current wheeze and life-time wheeze were more frequent in patients with VDGF exposure, which was associated with poorer health status (Table 2).

\section{Work disability}

COPD patients with VDGF exposure reported significantly more often an impact of their respiratory situation on their ability to work: $28.5 \%$ of VDGF-exposed subjects had to stop working definitely due to breathing difficulties vs $20.3 \%$ in non-exposed patients. In addition, $34.7 \%$ (vs $25.4 \%$ ) had to stop working transiently because they experienced respiratory problems. Altogether, only $36.8 \%$ of VDGF-exposed subjects (vs $54.3 \%$ of nonexposed subjects) reported no impact of their breathing situation on work.

Main differences between VDGF + and VDGF- COPD patients are summarized in Figure 1.

\section{Discussion}

In this patient series, the clinical characteristics of COPD appeared to be modulated by occupational exposures: patients reporting exposure to vapors, dust, gas or fumes at some point during their career also reported more frequently a history of hay fever, current wheeze and transient or permanent occupational disability. They were older and predominantly men with less current and cumulative smoking, despite similar severity of airflow obstruction. This is the first patient series identifying such specific clinical characteristics associated with occupational exposures in smokers and ex-smokers with COPD.

\section{Role of atopy in the development of COPD related to occupational exposures}

Since the late 1960s, it has been known that, although cigarette smoking is a risk factor for COPD, only 20 to $30 \%$ of cigarette smokers develop airways disease, suggesting that genetic susceptibility plays an important role as a determinant of disease occurrence.

In our cohort, occupational exposures were associated with atopy, despite the fact that all COPD patients were smokers or ex-smokers. This observation suggests that atopy and at least some occupational exposures interact to favour the development of the disease. Some decades ago, the Dutch hypothesis suggested that asthma and COPD are different manifestations of a single disease entity, called chronic nonspecific lung disease. It was suggested that endogenous factors (e.g., sex and age), environmental factors (e.g., allergens, occupation, and smoking) and genetic factors (including those predisposing to atopy and airway hyperresponsiveness) all play a role in the pathogenesis of the disease $[18,19]$.

Indeed, there is evidence that atopy, independently of its association with bronchial hyperesponsiveness, may be associated or have a role in the pathogenesis of COPD $[18,20]$. In a general population study, COPD was associated not only with smoking but also with occupational exposures and hay fever [21]. Other studies found an inverse association between atopy, as defined by IgE level, and the FEV1/FVC ratio, independently of smoking status [22]. Some genes, such as those coding IL-13 and IL-17F, might be involved in a global model of shared genetic 
Table 2 Symptoms according to VDGF exposure

\begin{tabular}{|c|c|c|c|c|}
\hline & All $n=591$ & VDGF $+\mathrm{N}=209$ & VDGF - 382 & $P$ value \\
\hline Chronic bronchitis (\%) & 73.3 & 75.3 & 72.2 & NS (a) \\
\hline Shortness of breath (MRC) & $2[1-2]$ & $2[1-2]$ & $2[1-2]$ & NS (b) \\
\hline Life-time wheeze (\%) & 65 & 71.9 & 61.1 & 0.0371 (a) \\
\hline Exacerbations/patient/yr & $1[0-3]$ & $1[0-3]$ & $1[0-3]$ & NS (b) \\
\hline $\mathrm{FEV}_{1}$ (postBD, \% predicted) & 49 [35-66] & $51.6[37.2-67.1]$ & $47.2[33.7-65.3]$ & $0.08(b)$ \\
\hline GOLD stages (\%) & & & & 0.15 (a) \\
\hline । & 5.6 & 7.7 & 4.5 & \\
\hline$\|$ & 43 & 44.5 & 42.2 & \\
\hline III & 33.2 & 33.5 & 33 & \\
\hline IV & 18.3 & 14.4 & 20.4 & \\
\hline Current sputum $^{1}$ & $2[1-4]$ & $3[1-4]$. & $2[1-4]$. & 0.035 (b) \\
\hline Current wheeze $^{1 *}$ & $1[0-2]$ & $2[0-3]$. & $1[0-2]$. & 0.002 (b) \\
\hline Work related respiratory disability * & $1[0-1]$ & $1[0-2]$ & $0[0-1]$ & 0.001 (b) \\
\hline SGRQ total score * & $43.7[30.3-60.0]$ & $46.2[32.5-63.4]$ & 42.0 [29.9-58.2] & NS (b) \\
\hline
\end{tabular}

': during the previous year (answers to SGRQ questions, symptoms domain).

*: analysis restricted to patients with available SGRQ: $n=424$ (VDGF+: $n=144 ;$ VDGF-: $n=280$ ). Answers were converted to continuous variables. Data are median [Q1 - Q3] or \%.

(a) $=$ Chi-Square Test.

(b) = Wilcoxon rank-sum test.

$p$ values are for differences between VGDF + and VGDF.

factors for atopy, asthma and COPD [11,23]. Lastly, it could be hypothesized that, in predisposed subjects, tobacco smoking may facilitate the development of atopy through its effect on IgE levels [24]. In patients subsequently exposed to occupational sensitizing agents, this may lead to the development of asthma-like features.

\section{Association between occupational exposures, asthma-like symptoms and lung function}

Persistent wheeze, which was associated with VDGF exposure in our series of COPD patients, can be a feature of airway hyperresponsiveness (AHR) [25]. AHR is a cardinal feature of asthma [26] and may contribute to the development of COPD [27]. Indeed, several studies found an increase in the risk of COPD in patients reporting a personal history of asthma or AHR $[8,28]$.

A longitudinal study of males with early COPD suggested that occupational exposure to fumes could be associated with an increased rate of decline of lung function [29]. However, in our population, lung function of exposed patients did not differ from that of patients with no reported occupational exposure. This discrepancy could relate to the lower cumulative smoking in exposed patients, or to an improvement in occupational conditions with aging, related to seniority in the job [30].

\section{Association between occupational exposures and respiratory disability}

In subjects with COPD, exposure to VDGF appears to promote transient or even permanent work loss due to respiratory disability. Only a few studies reported work loss associated with COPD. In the ECRHS, which included adults aged 20 to 44 years, job change due to breathing difficulties at work was reported by $4 \%$ of the whole studied population. This figure increased to $11 \%$ in subjects reporting either asthma or chronic bronchitis [31]. In the confronting COPD international survey (mean age 63.3 years), more than one third of persons with COPD (35.7\%) reported that their condition kept them from working [32]. In a community based cohort study using structured telephone interviews of 234 COPD patients, $25 \%$ reported respiratory disability at work and 16\% reported both VDGF exposures and respiratory-related work disability [6]. In a patient series of 185 male patients, 34 had become unemployed (18\%) due to COPD [9]. Our patient series is in agreement with these studies, with $28.5 \%$ of patients reporting cessation of work due to breathing, which is likely associated to both social and economical consequences.

\section{Accuracy of exposure assessment and other limitations and strengths of the study}

Assessment of occupational exposure was relatively crude in this study, since self-reported exposure based on a single item is subject to recall bias or subjective influences, in contrast to job-exposure matrix (JEM), which is considered as the "gold standard". However, previous studies performed in the general population suggest that, when compared to complex assessments such as job-exposure matrices, self-reported exposures 


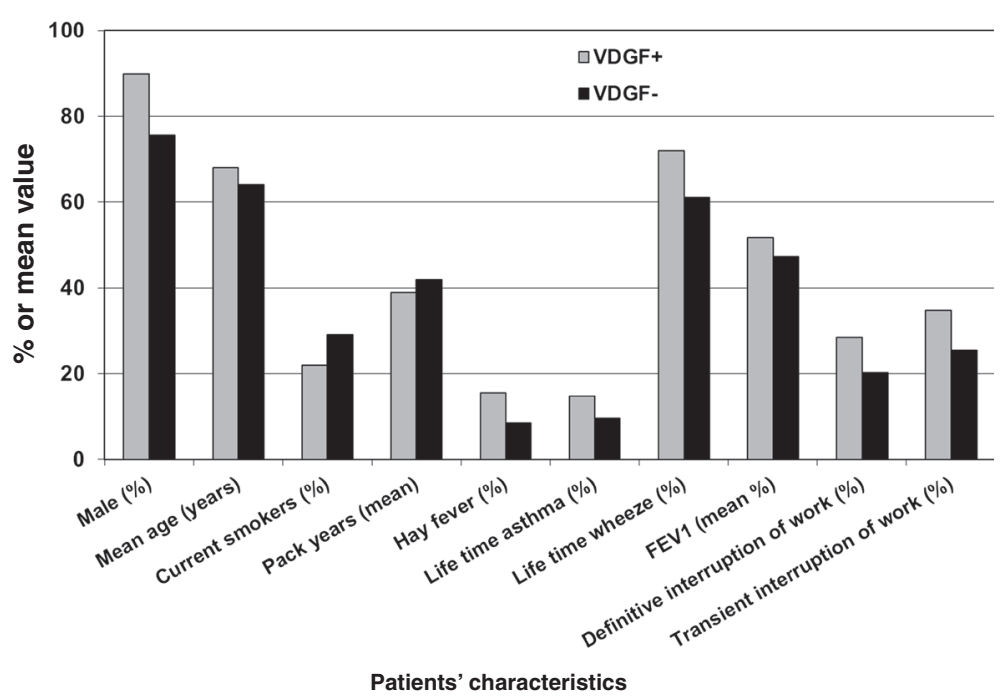

Figure 1 Main differences between VDGF + and VDGF- COPD patients. All differences are significant at the $p<0.05$ level except life time asthma $(p=0.06)$ and FEV1 $(p=0.08)$. Reported definitive and transient interruptions of work are those related to respiratory problems.

are accurate to identify associations between occupation and disease [33]. For instance, in two cohort studies of adults with asthma, self-reported VDGF exposure was fairly sensitive (71\%) when compared to JEM-defined exposure [34] and performed well against a checklist of 16 specific exposures [35]. In addition, several studies found increased respiratory symptoms in association with selfreported VDGF exposure [36,37]. For instance, one study of subjects with established COPD showed that prior exposure to VDGF was associated with increased symptoms over a 1 year follow-up [6]. Finally and importantly, the job-exposure matrix analysis in our subjects reporting VDGF exposure confirmed the reality of exposure. In the present study, statistical analyses using job-exposure matrix were performed to explore the relationship between the type of exposure and the presence of atopy, hay fever, asthma and wheezing; however, due to the relatively low number of patients in each individual category, it was not possible to draw any firm conclusion (data not shown).

Since patients recruited in the real-life observational Initiatives $\mathrm{BPCO}$ cohort are all followed in tertiary care centers, they cannot be considered as representative of the general COPD population. In addition, although centers were asked to include all consecutive COPD patients visiting their clinic, it is likely that recruitment was not exhaustive and varied with local resources affected to the study, competitive studies (subjects could not be included in the cohort if they participated to another study) and the effective duration of each center's participation to the cohort constitution. However, although we cannot formally test the issue of selection bias, it must be noted that (i) the study protocol did not mention any specific guidance on risk factors and (ii) the proportion of patients with occupational exposures is similar to what has been reported in other cohorts. Therefore, a selection bias appears quite unlikely to influence the results of the present analyses.

Pre-bronchodilator FEV1 was not available for all subjects, which prevented us from including reversibility data in the studied variables. Patients exposed to VDGF could have more reversible airway obstruction, corresponding to the asthma-like symptoms (increased frequency of current wheeze) that were reported. However, we have no way to test this hypothesis and, in general, the relationship between symptoms and lung function variables including reversibility is poor. Along the same line, it would have been interesting to compare lung volumes, diffusing capacity, and non-specific bronchial hyperresponsiveness between exposed and unexposed patients. However, these measurements were unavailable in most subjects, as explained by the real-life nature of the cohort. Similar concerns can be expressed for skin prick tests.

A particular aspect of this patient series is that, to limit the risk of including predominantly asthmatic subjects with fixed airflow obstruction, it happened that all centers included only smokers or ex-smokers. This was both a strength since it "secured" the diagnosis of COPD, and a limitation in that it precluded analyzes of the role of occupational exposures in never-smokers. However, it did not prevent from identifying specific clinical features in exposed patients. Similar studies in never-smoking subjects with COPD would be of interest to determine 
whether our observations are the results of VDGF only, or of VDGF-cigarette smoke interactions.

Another area of interest is the respective weight of risk factors as determinants of the severity of airflow obstruction. Although presented analyses were not initially designed to address this research question, we explored this issue using two multivariate models: one was a logistic regression analysis with GOLD stage as dependent variable, the other was a multilinear regression with $\mathrm{FEV}_{1}$ (\% predicted) as the dependent variable. Smoking was accounted for using cumulative consumption in pack-years and smoking status at inclusion (present vs past smoking). Variables reflecting atopy were patientreported hay fever and familial history of atopy. With the first model, only less than $2 \%\left(R^{2}=0,018\right.$, $p$ value of the model: 0.46) of variations in the GOLD classification could be explained by risk factors. In the second model, $\mathrm{R}^{2}$ was even lower $(0.0089$, with a $\mathrm{p}$ value for the model of 0.28 ). Thus, it can be concluded that, in this population of smokers and ex-smokers, risk factors (age, smoking, occupational exposure, atopy) are very poorly correlated with the severity of airflow obstruction, which makes it impossible to draw any conclusion as to their respective weight.

\section{Conclusions}

This is the first study to demonstrate that occupational exposures are associated with distinct clinical characteristics in smokers and ex-smokers with COPD, i.e. (i) older age and predominantly male gender, (ii) more frequent respiratory-related work disability or handicap and (iii) increased prevalence of hay fever, asthma, current sputum production, lifetime and current wheezing. This may help targeting subjects for preventive measures. Our findings need to be confirmed and expanded in other cohorts, which should also aim at identifying more precisely which occupational pollutants are involved and which exposure thresholds (dose, duration, frequency) are associated with an increased risk.

\section{Competing interest}

The authors declare they have no competing interests

\section{Authors' contributions}

All authors participated to the study design, data collection, manuscript revision and approval of the final version. D Caillaud and N Roche wrote the paper and interpreted the data, which was analyzed by JL Paillasseur, statistician. All authors read and approved the final manuscript.

\section{Acknowledgments}

Other members of the initiative COPD study group: A Cuvelier (Rouen), C Gut-Gobert (Brest), P Nesme-Meyer (Lyon), I Tillie-Leblond (Lille), C Perrin (Cannes), C Raherison (Bordeaux). This study was supported by unrestricted grants from Boehringer Ingelheim and Pfizer. Logistical and organizational support were provided by Lob Conseils.

\section{Author details}

'Service de Pneumologie, Hôpital Gabriel Montpied, Montalembert Str, Clermont-Ferrand, 63003, France. ${ }^{2}$ Service de Pneumologie, $\mathrm{CHU}$ de Nice, 30 voie romaine Av, Nice, 06000, France. ${ }^{3}$ Service de Pneumologie, Hôpital
Antoine Gayraud, BP 1014 Carcassonne, 11890, France. ${ }^{4}$ Clinique des voies respiratoires, Hopital Larrey, 24, Pouvourville Str, Toulouse, 31059, France. ${ }^{5}$ Département des Maladies Respiratoires, AP-HM, Université de la Méditerranée, Bourelly Str, Marseille, 13915, France. 'Service de Pneumologie, Hôpital Cochin, AP-HP and Paris-Descartes University, 27, Faubourg St-Jacques Str, Paris, 75014, France. ${ }^{7}$ Service de Pneumologie, CHU Saint Etienne, Albert Raimond Av, Saint Etienne, 42055, France. ${ }^{8}$ Service de Pneumologie, Hôpital Bichat, 46, Henri Huchard Str, Paris, 75018, France. 'Service de Pneumologie, CHG, 1208, colonel Picot Av, Toulon, 83056, France. ${ }^{10}$ Service de Pneumologie, Hôpital Calmette, J Leclerq bd, Lille, 59037, France. " ${ }^{11}$ Service de Pneumologie, Hôpital Pontchaillou, 2, Henri Le Guillou Str, Rennes, 35000, France. ${ }^{12}$ Clindatafirst, 12, Prés Av, St Quentin en Yvelines, 78059, France. ${ }^{13}$ Service de Pneumologie, Hôtel Dieu, AP-HP and Paris-Descartes University, Parvis Notre Dame Place, Paris, 75004 France.

Received: 13 July 2011 Accepted: 28 March 2012 Published: 26 April 2012

\section{References}

1. Fletcher $C$, Peto R: The natural history of chronic airflow obstruction. $\mathrm{Br}$ Med J 1977, 1(6077):1645-1648.

2. Salvi SS, Barnes PJ: Chronic obstructive pulmonary disease in nonsmokers. Lancet 2009, 374(9691):733-743.

3. Eisner MD, Anthonisen N, Coultas D, Kuenzli N, Perez-Padilla R, Postma D, Romieu I, Silverman EK, Balmes JR: An official American Thoracic Society public policy statement: Novel risk factors and the global burden of chronic obstructive pulmonary disease. Am J Respir Crit Care Med 2010, 182(5):693-718.

4. Becklake MR: Occupational exposures: evidence for a causal association with chronic obstructive pulmonary disease. Am Rev Respir Dis 1989, 140(3 Pt 2): S85-S91.

5. Zock JP, Sunyer J, Kogevinas M, Kromhout H, Burney P, Anto JM: Occupation, chronic bronchitis, and lung function in young adults. An international study. Am J Respir Crit Care Med 2001, 163(7):1572-1577.

6. Blanc PD, Eisner MD, Trupin L, Yelin EH, Katz PP, Balmes JR: The association between occupational factors and adverse health outcomes in chronic obstructive pulmonary disease. Occup Environ Med 2004, 61(8):661-667.

7. Blanc PD, Iribarren C, Trupin L, Earnest G, Katz PP, Balmes J, Sidney S, Eisner MD: Occupational exposures and the risk of COPD: dusty trades revisited. Thorax 2009, 64(1):6-12.

8. Weinmann $\mathrm{S}$, Vollmer WM, Breen V, Heumann M, Hnizdo E, Villnave J, Doney B, Graziani M, McBurnie MA, Buist AS: COPD and occupational exposures: a case-control study. J Occup Environ Med 2008, 50(5):561-569.

9. Rodriguez E, Ferrer J, Marti S, Zock JP, Plana E, Morell F: Impact of occupational exposure on severity of COPD. Chest 2008, 134(6):1237-1243.

10. Viegi G, Di Pede C: Chronic obstructive lung diseases and occupational exposure. Curr Opin Allergy Clin Immunol 2002, 2(2):115-121.

11. Beghe B, Hall IP, Parker SG, Moffatt MF, Wardlaw A, Connolly MJ, Fabbri LM, Ruse C, Sayers I: Polymorphisms in IL13 pathway genes in asthma and chronic obstructive pulmonary disease. Allergy 2010, 65(4):474-481.

12. Burgel PR, Nesme-Meyer P, Chanez P, Caillaud D, Carre P, Perez T, Roche N: Cough and sputum production are associated with frequent exacerbations and hospitalizations in COPD subjects. Chest 2009, 135(4):975-982.

13. Rabe KF, Hurd S, Anzueto A, Barnes PJ, Buist SA, Calverley P, Fukuchi Y, Jenkins C, Rodriguez-Roisin R, van Weel C, et al: Global strategy for the diagnosis, management, and prevention of chronic obstructive pulmonary disease: GOLD executive summary. Am J Respir Crit Care Med 2007, 176(6):532-555.

14. Jones PW, Quirk FH, Baveystock CM, Littlejohns P: A self-complete measure of health status for chronic airflow limitation. The St. George's Respiratory Questionnaire. Am Rev Respir Dis 1992, 145(6):1321-1327.

15. Quanjer PH, Tammeling GJ, Cotes JE, Pedersen OF, Peslin R, Yernault JC: Lung volumes and forced ventilatory flows. Report Working Party Standardization of Lung Function Tests, European Community for Steel and Coal. Official Statement of the European Respiratory Society. Eur Respir J Suppl 1993, 16:5-40.

16. Sunyer J, Zock JP, Kromhout H, Garcia-Esteban R, Radon K, Jarvis D, Toren K, Kunzli N, Norback D, d'Errico A, et al: Lung function decline, chronic bronchitis, and occupational exposures in young adults. Am J Respir Crit Care Med 2005, 172(9):1139-1145

17. Kogevinas M, Anto JM, Sunyer J, Tobias A, Kromhout H, Burney P: Occupational asthma in Europe and other industrialised areas: a 
population-based study. European Community Respiratory Health Survey Study Group. Lancet 1999, 353(9166):1750-1754.

18. O'Connor GT, Sparrow D, Weiss ST: The role of allergy and nonspecific airway hyperresponsiveness in the pathogenesis of chronic obstructive pulmonary disease. Am Rev Respir Dis 1989, 140(1):225-252.

19. Postma DS, Kerkhof M, Boezen HM, Koppelman GH: Asthma and chronic obstructive pulmonary disease: common genes, common environments? Am J Respir Crit Care Med 2011, 183(12):1588-1594.

20. Meijer $E$, Kromhout $H$, Heederik D: Respiratory effects of exposure to low levels of concrete dust containing crystalline silica. Am J Ind Med 2001, 40 (2):133-140.

21. Melville AM, Pless-Mulloli T, Afolabi OA, Stenton SC: COPD prevalence and its association with occupational exposures in a general population. Eur Respir J 2010, 36:488-493.

22. Burrows B, Bloom JW, Traver GA, Cline MG: The course and prognosis of different forms of chronic airways obstruction in a sample from the general population. N Engl J Med 1987, 317(21):1309-1314.

23. Hizawa N, Kawaguchi M, Huang SK, Nishimura M: Role of interleukin-17F in chronic inflammatory and allergic lung disease. Clin Exp Allergy 2006, 36 (9):1109-1114.

24. Oryszczyn MP, Annesi-Maesano I, Charpin D, Paty E, Maccario J, Kauffmann F: Relationships of active and passive smoking to total lgE in adults of the Epidemiological Study of the Genetics and Environment of Asthma, Bronchial Hyperresponsiveness, and Atopy (EGEA). Am J Respir Crit Care Med 2000, 161(4 Pt 1):1241-1246.

25. Xu X, Rijcken B, Schouten JP, Weiss ST: Airways responsiveness and development and remission of chronic respiratory symptoms in adults. Lancet 1997, 350(9089):1431-1434.

26. Carey VJ, Weiss ST, Tager IB, Leeder SR, Speizer FE: Airways responsiveness, wheeze onset, and recurrent asthma episodes in young adolescents. The East Boston Childhood Respiratory Disease Cohort. Am J Respir Crit Care Med 1996, 153(1):356-361.

27. Brutsche MH, Downs SH, Schindler C, Gerbase MW, Schwartz J, Frey M, Russi EW, Ackermann-Liebrich U, Leuenberger P: Bronchial hyperresponsiveness and the development of asthma and COPD in asymptomatic individuals: SAPALDIA cohort study. Thorax 2006, 61(8):671-677.

28. Chapman KR, Mannino DM, Soriano JB, Vermeire PA, Buist AS, Thun MJ, Connell C, Jemal A, Lee TA, Miravitlles M, et al: Epidemiology and costs of chronic obstructive pulmonary disease. Eur Respir J 2006, 27(1):188-207.

29. Harber P, Tashkin DP, Simmons M, Crawford L, Hnizdo E, Connett J: Effect of occupational exposures on decline of lung function in early chronic obstructive pulmonary disease. Am J Respir Crit Care Med 2007, 176 (10):994-1000.

30. Kromhout $\mathrm{H}$, Vermeulen $\mathrm{R}$ : Long-term trends in occupational exposure: Are they real? What causes them? What shall we do with them? Ann Occup Hyg 2000, 44(5):325-327.

31. Blanc PD, Burney P, Janson C, Toren K: The prevalence and predictors of respiratory-related work limitation and occupational disability in an international study. Chest 2003, 124(3):1153-1159.

32. Rennard S, Decramer M, Calverley PM, Pride NB, Soriano JB, Vermeire PA, Vestbo J: Impact of COPD in North America and Europe in 2000: subjects' perspective of Confronting COPD International Survey. Eur Respir J 2002, 20(4):799-805.

33. Post WK, Heederik D, Kromhout H, Kromhout D: Occupational exposures estimated by a population specific job exposure matrix and 25 year incidence rate of chronic nonspecific lung disease (CNSLD): the Zutphen Study. Eur Respir J 1994, 7(6):1048-1055.

34. Quinlan PJ, Earnest G, Eisner MD, Yelin EH, Katz PP, Balmes JR, Blanc PD: Performance of self-reported occupational exposure compared to a job-exposure matrix approach in asthma and chronic rhinitis. Occup Environ Med 2009, 66(3):154-160.

35. Blanc PD, Eisner MD, Balmes JR, Trupin L, Yelin EH, Katz PP: Exposure to vapors, gas, dust, or fumes: assessment by a single survey item compared to a detailed exposure battery and a job exposure matrix. Am $J$ Ind Med 2005, 48(2):110-117.

36. Krzyzanowski M, Jedrychowski W: Occupational exposure and incidence of chronic respiratory symptoms among residents of Cracow followed for 13 years. Int Arch Occup Environ Health 1990, 62(4):311-317.

37. Xu X, Christiani DC, Dockery DW, Wang L: Exposure-response relationships between occupational exposures and chronic respiratory illness: a community-based study. Am Rev Respir Dis 1992, 146(2):413-418. doi:10.1186/1471-2458-12-302

Cite this article as: Caillaud et al:: Association between occupational exposure and the clinical characteristics of COPD. BMC Public Health 2012 12:302.

\section{Submit your next manuscript to BioMed Central and take full advantage of:}

- Convenient online submission

- Thorough peer review

- No space constraints or color figure charges

- Immediate publication on acceptance

- Inclusion in PubMed, CAS, Scopus and Google Scholar

- Research which is freely available for redistribution 